\title{
Measurement of Third-Order Nonlinear Susceptibilities by Non-Phase Matched Third-Harmonic Generation
}

\author{
M. Thalhammer and A. Penzkofer \\ Naturwissenschaftliche Fakultät II - Physik, Universität, D-8400 Regensburg, \\ Fed. Rep. Germany
}

Received 1 June 1983/Accepted 5 August 1983

\begin{abstract}
The third-order susceptibilities $\chi_{x x x x}^{(3)}\left(-\omega_{3} ; \omega_{1}, \omega_{1}, \omega_{1}\right)$ of some liquids, solids and air are determined by third-harmonic generation. The samples are placed behind the focal region of a laser beam in an evacuated environment to avoid third-harmonic generation of the surroundings. For fluid media the sample cell is made out of two thin fused quartz plates and oriented to an angle of zero net third-harmonic production in each window (minimum Maker fringe position).
\end{abstract}

PACS: 42.65

The measurement of third-order nonlinear susceptibilities $\chi^{(3)}\left(-\omega_{3} ; \omega_{1}, \omega_{1}, \omega_{1}\right)$ responsible for thirdharmonic generation is aggravated by disturbing light production in surrounding media (sample cell, air). Avoiding the influence of the surrounding substances in the light path by tight focussing (sample length longer than confocal parameter) results in zero thirdharmonic generation under phase-matched condition and for positive phase-mismatch $\Delta k=k_{3}-3 k_{1}>0$ (normal dispersive media). Only in anomalous dispersive matter light generation at frequency $\omega_{3}$ occurs $[1,2]$. In a collimated pump beam (frequency $\omega_{1}$ ) the third-harmonic light is periodically generated and annihilated for $\Delta k \neq 0$ and efficient light generation requires $\Delta k=0$. Circularly polarized laser light does not generate third-harmonic light in transparent media at all [6].

Third-order nonlinear susceptibility values $\chi^{(3)}\left(-\omega_{3}\right.$; $\omega_{1}, \omega_{1}, \omega_{1}$ ) of gases were obtained by putting a gas cell with its entrance window (absorbing at $\omega_{3}$ ) in the focal plane of a laser [1]. The susceptibilities of some solids were measured in reflection [3]. A comparison of third-harmonic generation with cascading secondorder processes was used to derive $\chi^{(3)}\left(-\omega_{3} ; \omega_{1}, \omega_{1}\right.$, $\left.\omega_{1}\right)$ values for liquids and solids $[4,5]$. In mixtures of substances with normal and anomalous dispersion optimum third-harmonic conditions were achieved [6-10] and nonlinear susceptibility values could be obtained.
In this paper we report on an accurate method to determine the third-order nonlinear susceptibilities $\chi^{(3)}\left(-\omega_{3} ; \omega_{1}, \omega_{1}, \omega_{1}\right)$ of solids, liquids and gases. Third-harmonic generation in a slightly diverging beam (thin sample behind focal plane of a lens) is studied. Third-harmonic generation in air along the path of the laser beam is avoided by putting the sample into a vacuum chamber. The entrance and exit windows of the sample cell for liquids and gases are made out of thin plane fused silica plates (thickness: $\approx 0.2 \mathrm{~mm}$ ). By tilting the cell to a Maker fringe minimum position for each window [11] no thirdharmonic light is produced in each of the windows. The cell is slightly wedged in order to record a Maker fringe curve when the filled cell is laterally shifted relative to the light path.

\section{Theory}

The calculation of third-harmonic light generation starts from the wave equation

$\frac{\partial^{2}}{\partial z^{2}} \mathbf{E}-\frac{n^{2}}{c^{2}} \frac{\partial^{2}}{\partial t^{2}} \mathbf{E}-\frac{\alpha n}{c} \frac{\partial}{\partial t} \mathbf{E}=\mu_{0} \frac{\partial^{2}}{\partial t^{2}} \mathbf{P}_{\mathrm{NL}}$,

where $\mathbf{E}$ is the electrical field strength and $\mathbf{P}_{\mathrm{NL}}$ the nonlinear polarization; $n$ and $\alpha$ are the refractive index and the linear absorption coefficient, respectively. The 
(a)

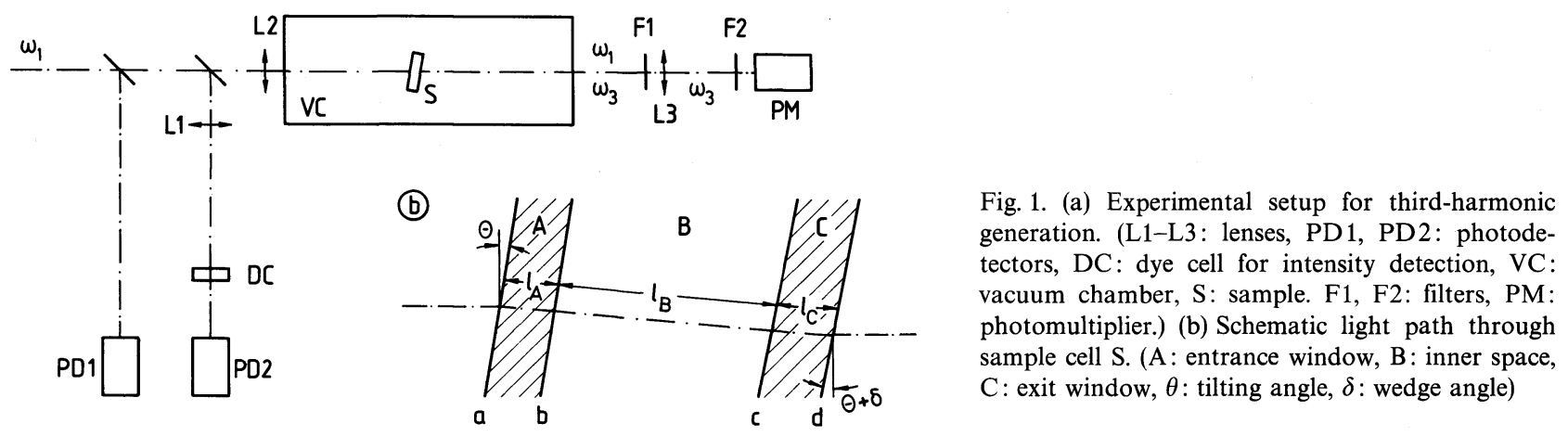

nonlinear polarization which is responsible for thirdharmonic generation is [12]

$\mathbf{P}_{\mathrm{NL}}=4 \varepsilon \chi^{(3)}: \mathbf{E E E}$

with $\chi^{(3)}$ being the third-order nonlinear susceptibility tensor.

Equation (1) is solved with the plane-wave ansatz for the third-harmonic generation process $\omega_{1}+\omega_{1}$ $+\omega_{1} \rightarrow \omega_{3}$

$$
\begin{aligned}
\mathbf{A}= & \mathbf{A}_{1}+\mathbf{A}_{3}=\frac{1}{2}\left\{\mathbf{A}_{10} \exp \left[\mathrm{i}\left(k_{1} z-\omega_{1} t\right)\right]\right. \\
& \left.+\mathbf{A}_{30} \exp \left[\mathrm{i}\left(k_{3} z-\omega_{3} t\right)\right]+\text { c.c. }\right\},
\end{aligned}
$$

where $\mathbf{A}$ stands for $\mathbf{E}$ and $\mathbf{P}_{\mathrm{NL}} \cdot \mathbf{A}_{10}$ and $\mathbf{A}_{30}$ are the amplitudes at $\omega_{1}$ and $\omega_{3}$, respectively. Using the slowly varying amplitude approximation and the transformation $z^{\prime}=z$ and $t^{\prime}=t-n z / c$ leads to $(\beta=1,3)$

$\frac{\partial}{\partial z^{\prime}} \mathbf{E}_{\beta 0}+\frac{\alpha_{\beta}}{2} \mathbf{E}_{\beta 0}=\frac{\mathrm{i} c \mu_{0} \omega_{\beta}}{2 n_{\beta}} \mathbf{P}_{\mathrm{NL}, \beta 0}$.

Neglecting the effect of $\mathbf{P}_{\mathrm{NL}, 10}$ on $\mathbf{E}_{10}$, the pump laser field amplitude is given by

$\mathbf{E}_{10}\left(z^{\prime}\right)=\mathbf{E}_{10}\left(z_{0}\right) \exp \left[-\alpha_{1}\left(z^{\prime}-z_{0}\right) / 2\right]$.

In the experiments linearly polarized laser light is used, i.e. $E_{10, x}=E_{10}, E_{10, y}=E_{10, z}=0$. For this situation the nonlinear polarization $\mathbf{P}_{\mathrm{NL}, 30}$ reduces to

$$
\begin{aligned}
P_{\mathrm{NL}, 30, x}\left(z^{\prime}\right)= & \varepsilon_{0} \chi_{x x x x}^{(3)}\left(-\omega_{3} ; \omega_{1}, \omega_{1}, \omega_{1}\right) E_{10}^{3}\left(z^{\prime}\right) \\
& \cdot \exp \left\{-\mathrm{i}\left[\Delta k\left(z^{\prime}-z_{0}\right)+\varphi\left(z_{0}\right)\right]\right\}
\end{aligned}
$$

and $P_{\mathrm{NL}, 30, y}=P_{\mathrm{NL}, 30, z}=0$ for isotropic media and all crystalline classes except triclinic and monoclinic. $\Delta k$ $=k_{3}-3 k_{1}=\left(n_{3} \omega_{3}-3 n_{1} \omega_{1}\right) / c=3 \omega_{1}\left(n_{3}-n_{1}\right) / c$ is the wave vector mismatch. $\varphi\left(z_{0}\right)$ is the phase of the nonlinear polarization at the initial position $z_{0}$. In the further discussion $\chi_{x x x x}^{(3)}\left(-\omega_{3} ; \omega_{1}, \omega_{1}, \omega_{1}\right)$ is abbreviated by $\chi^{(3)}$.
Insertion of (5) and (6) into (4) gives $\left(E_{30, x}=E_{30} ; E_{30, y}\right.$ $=E_{30, z}=0, z^{\prime}>z_{0}$ )

$$
\begin{aligned}
\frac{\partial}{\partial z^{\prime}} & E_{30}+\frac{\alpha_{3}}{2} E_{30} \\
= & \frac{\mathrm{i} \omega_{3}}{2 n_{3} c} \chi^{(3)} E_{10}^{3}\left(z_{0}\right) \\
& \cdot \exp \left\{-\frac{3 \alpha_{1}\left(z^{\prime}-z_{0}\right)}{2}-\mathrm{i}\left[\Delta k\left(z^{\prime}-z_{0}\right)+\varphi\left(z_{0}\right)\right]\right\} .
\end{aligned}
$$

The solution of (7) is $\cdot \exp \left[-\frac{\alpha_{3}}{2}\left(z^{\prime}-z_{0}\right)\right]$

$$
\begin{aligned}
E_{30}\left(z^{\prime}\right)= & E_{30}\left(z_{0}\right)+\frac{\mathrm{i} \omega_{3}}{2 n_{3} c} \chi^{(3)} E_{10}^{3}\left(z_{0}\right) \\
& \cdot \exp \left[-\frac{\alpha_{3}}{2}\left(z^{\prime}-z_{0}\right)-\mathrm{i} \varphi\left(z_{0}\right)\right] \\
& \cdot \frac{\exp \left\{\left[\left(\alpha_{3}-3 \alpha_{1}\right) / 2-\mathrm{i} \Delta k\right]\left(z^{\prime}-z_{0}\right)\right\}-1}{\left(\alpha_{3}-3 \alpha_{1}\right) / 2-\mathrm{i} \Delta k}
\end{aligned}
$$

For transparent media $\left(\alpha_{1}=\alpha_{3}=0\right)$ Eq. (8) simplifies to

$$
\begin{aligned}
E_{30}\left(z^{\prime}\right)= & E_{30}\left(z_{0}\right)+\frac{i \omega_{3}}{n_{3} c \Delta k} \chi^{(3)} E_{10}^{3}\left(z_{0}\right) \\
& \cdot \exp \left\{-\mathrm{i}\left[\frac{\Delta k\left(z^{\prime}-z_{0}\right)}{2}+\varphi\left(z_{0}\right)\right]\right\} \\
& \cdot \sin \left[\Delta k\left(z^{\prime}-z_{0}\right) / 2\right] .
\end{aligned}
$$

Equation (9) indicates that the contribution to thirdharmonic light generation $E_{30}\left(z^{\prime}\right)-E_{30}\left(z_{0}\right)$ in a transparent medium of length $z^{\prime}-z_{0}$ is zero if $z^{\prime}-z_{0}$ $=2 m l_{\text {coh }}$, where $l_{\text {coh }}=\pi / \Delta k$ is the coherence length and $m$ is an integer. The thicknesses of our windows are adjusted to this length condition (entrance window $l_{A}=34 l_{\text {Coh }}$, exit window $l_{C}=32 l_{\text {Coh }}$, Fig. 1 b) in order to avoid contributions of the cell windows to the thirdharmonic light generated in the sample.

The light path through the sample cell is shown schematically in Fig. 1b. The cell has a wedge $\delta$. Its entrance face is tilted to an angle $\theta$ to the input light 
direction. The light is polarized perpendicular to the plane of incidence. The input light amplitude $E_{30}\left(a_{-}\right)$ before the entrance window is made negligibly small by focusing the pump laser into a long vacuum chamber and positioning the sample in the focal region behind the focal plane (Fig. 1a). (Subscripts - and + indicate positions before and after an interface, respectively:) At the end of the transparent entrance window $A$ at position $b_{-}$it is $E_{30}\left(b_{-}\right)=E_{30}\left(l_{A}\right)=0$, since $E_{30}\left(z_{0}=0\right)=E_{30}\left(a_{+}\right)=0$ and $l_{A}=2 m_{A} l_{\text {coh }}$ with $m_{A}=17,(9)$. At the end $c_{-}$of the inner space of the cell $B$ of thickness $l_{B}$ the amplitude $E_{30}\left(c_{-}\right)=E_{30}\left(l_{A}+l_{B}\right)$ is given by (8) with $E_{30}\left(z_{0}=l_{A}\right)=0$ and $z^{\prime}-z_{0}=l_{B}$. The exit window $C$ transfers the generated signal $E_{30}\left(l_{A}+l_{B}\right)$ unchanged to the outside (except reflection losses, see below) since its thickness is an integer multiple of $2 l_{\text {coh }}$ [see (9), $E_{30}\left(z^{\prime}=l_{A}+l_{B}+l_{C}\right)=E_{30}\left(z_{0}\right.$ $\left.=l_{A}+l_{B}\right)$, since $\left.\sin \left[\Delta k\left(z^{\prime}-z_{0}\right) / 2\right]=\sin \left(\Delta k l_{C} / 2\right)=0\right]$.

The generated third-harmonic intensity is calculated from (8) by using the relation $I=\left(n c \varepsilon_{0} / 2\right)|E|^{2}$. For the conditions stated above $\left[E_{30}\left(a_{+}\right)=0, l_{A}=2 m_{A} l_{\text {coh }}\right]$ the intensity at interface $c$ is

$I_{3}\left(c_{-}\right)=\kappa\left|\chi^{(3)}\right|^{2} I_{1}^{3}\left(b_{+}\right)$

with

$\kappa=\frac{\omega_{3}^{2}\left\{\exp \left(-3 \alpha_{1} l_{B}\right)+\exp \left(-\alpha_{3} l_{B}\right)-2 \exp \left[-\left(\alpha_{3}+3 \alpha_{1}\right) l_{B} / 2\right] \cos \left(\Delta k l_{B}\right)\right\}}{n_{3} n_{1}^{3} c^{4} \varepsilon_{0}^{2}\left[\left(\alpha_{3}-3 \alpha_{1}\right)^{2} / 4+\Delta k^{2}\right]}$.

For transparent media $\kappa$ simplifies to

$\kappa=\frac{\omega_{3}^{2}}{n_{3} n_{1}^{3} c^{4} \varepsilon_{0}^{2}} \frac{\sin ^{2}\left(\Delta k l_{B} / 2\right)}{(\Delta k / 2)^{2}}$.

In the experiments the energy conversion ratio $\eta_{\exp }$ $=W_{3}\left(d_{+}\right) / W_{1}\left(a_{-}\right)$of third-harmonic pulse energy $W_{3}\left(d_{+}\right)$after the end of the sample to incident fundamental pulse energy $W_{1}\left(a_{-}\right)$before the entrance window is measured. From (10) the energy conversion $\eta=W_{3}\left(c_{-}\right) / W_{1}\left(b_{+}\right)$may be calculated. For a Gaussian temporal and spatial pulse shape one obtains

$\eta=\frac{W_{3}\left(c_{-}\right)}{W_{1}\left(b_{+}\right)}=\frac{\kappa}{3^{3 / 2}}\left|\chi^{(3)}\right|^{2} I_{10}^{2}\left(b_{+}\right)$.

$I_{10}\left(b_{+}\right)$is the input peak intensity at the beginning of the inner space of the cell. The energies $W_{3}\left(c_{-}\right), W_{1}\left(b_{+}\right)$ and the intensity $I_{10}\left(b_{+}\right)$are related to the measurable quantities $W_{3}\left(d_{+}\right), W_{1}\left(a_{-}\right)$and $I_{10}\left(a_{-}\right)$by

$$
\begin{aligned}
& I_{1}\left(b_{+}\right)=I_{1}\left(a_{-}\right) \frac{\left[1-r_{\perp 1}^{2}(a)\right]\left[1-r_{\perp 1}^{2}(b)\right]}{M(a) M(b)}, \\
& W_{1}\left(b_{+}\right)=W_{1}\left(a_{-}\right)\left[1-r_{\perp 1}^{2}(a)\right]\left[1-r_{\perp 1}^{2}(b)\right], \\
& W_{3}\left(c_{-}\right)=\frac{W_{3}\left(d_{+}\right)}{\left[1-r_{\perp 3}^{2}(c)\right]\left[1-r_{\perp 3}^{2}(d)\right]},
\end{aligned}
$$

$r_{\perp i}(x)$ is the reflectivity of light of frequency $\omega_{i}$ at the interface $x(=a, b, c, d) .\left[r_{\perp}=-\sin \left(\theta_{i}-\theta_{t}\right) / \sin \left(\theta_{i}+\theta_{t}\right)\right.$, where $\theta_{i}$ and $\theta_{t}$ are the angles of incidence and refraction]. $M(a)$ and $M(b)$ denote the magnification of the beam diameter in the plane of refraction $\left(M=\cos \theta_{t} / \cos \theta_{i}\right) . \quad\left|\chi^{(3)}\right|$ is determined from (13) by measuring all quantities entering (11) and (13).

Using a cell with a slight wedge the $\cos \left(\Delta k l_{B}\right)$ dependence of $\eta,(11)$, is observed by transverse displacement of the sample. In case of strong dispersion $\cos \left(\Delta k l_{B}\right)$ averages already across the beam diameter $\left[\left\langle\cos \left(\Delta k l_{B}\right)\right\rangle=0\right]$.

\section{Experimental}

A passively mode-locked Nd-phosphate glass laser $\left(\tilde{v}_{1}\right.$ $=9480 \mathrm{~cm}^{-1}$ ) is used in the experiments. A single transform limited pulse is selected in the early part of the pulse train. Broadened spectra as they occur in later parts of the pulse train cause a spreading of $\Delta k$ due to the dispersion of the refractive index and wash out the Maker fringes. The selected pulse is increased in energy by double passage through a Nd-glass amplifier.
The set-up for $\chi^{(3)}$-measurement is displayed in Fig. 1a. The input pulse energy $W_{1}$ is registered with photodetector PD1. The input peak intensity $I_{10}$ is determined from energy-transmission measurements through a saturable absorber with detectors PD 2 and PD 1 [13]. The laser pulse is focused with a lens L 2 of $f=30 \mathrm{~cm}$ focal length. This lens is placed in front of a $80 \mathrm{~cm}$ long vacuum chamber (pressure: $\simeq 0.1 \mathrm{mbar}$ ). The sample is positioned $36 \mathrm{~cm}$ behind the lens $\mathrm{L} 2$. The laser peak intensity at the sample is in the range between $2 \times 10^{9}$ and $8 \times 10^{9} \mathrm{~W} / \mathrm{cm}^{2}$. In this intensity region light generation at $\omega_{3}$ by cascading parametric processes (parametric interaction $\omega_{1}+\omega_{1} \rightarrow \omega_{S}+\omega_{I}$ and frequency conversion $\omega_{1}+\omega_{S}+\omega_{I} \rightarrow \omega_{3}$ ) is negligible [14]. Behind the vacuum chamber the fundamental laser is filtered out with filters F1. The third-harmonic light is focused with lens L 3 to the photomultiplier PM which measures the generated light energy $W_{3}$. Detectors PD1 and PM were cross-calibrated by detecting the same second harmonic signal with both detectors and using spectral sensitivity curves for their response to the fundamental (PD1) and thirdharmonic frequency (PM).

The sample cell for liquids has a length of $l_{B}=2 \mathrm{~mm}$. Its opening is rectangular having a width of $9 \mathrm{~mm}$ and a height of $3 \mathrm{~mm}$ (small opening to avoid distortions in vacuum chamber). The wedge of the cell along the 


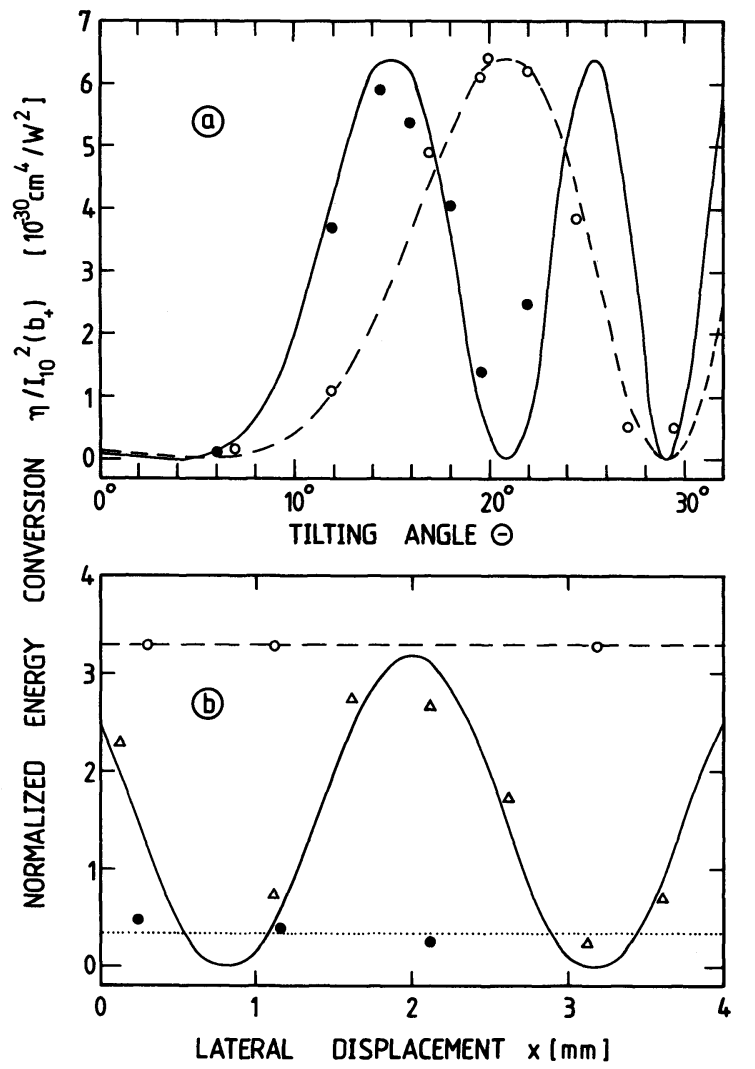

Fig. 2. (a) Third-harmonic generation in empty sample cell versus tilting angle $\theta$. Dashed curve $(\mathrm{O})$, entrance window (fused silica Suprasil I, thickness $d=0.222 \mathrm{~mm}$ ). Solid curve $(\bullet)$, empty cell consisting of entrance plate with $\theta_{\min }=6^{\circ}$ and exit plate with $\theta_{\min }=0^{\circ}$. [Curves calculated, (12) and (13).] (b) Third-harmonic generation versus lateral displacement $x$ of wedged cell. Tilting angle $\theta=\theta_{\min }=5^{\circ}$. Dotted curve $(\bullet)$, empty cell. Solid curve $(\triangle)$, methanol. Dashed curve $(O)$, benzene. (Curves are fitted to experimental points, not calculated)

$9 \mathrm{~mm}$ width is $\delta=0.46^{\circ}$. The Suprasil windows (microscope cover plates) have thicknesses of 0.222 and $0.209 \mathrm{~mm}$. They are pressed to the brass cell with brass fittings. Teflon washers are used for tightening. A cell of $12 \mathrm{~mm}$ length was used for the investigation of air.

Figure 2a depicts the normalized third-harmonic signal $S=\eta / I_{10}^{2}\left(b_{+}\right)$versus tilting angle $\theta$ for the entrance plate (dashed curve) and the empty cell (both windows, solid curve). Figure $2 \mathrm{~b}$ shows $S$ versus displacement $x$ at a tilting angle $\theta=\theta_{\text {min }}=5^{\circ}$ for the empty cell (dotted line), for methanol (full line) and benzene (dashed line). In case of methanol the modulation of $S(x)$ due to the $\cos \left(\Delta k l_{B}\right)$-dependence of (11) is clearly seen. For benzene the signal averages already within the laser diameter.

\section{Results}

The magnitude of the third-order nonlinear susceptibility

$$
\chi_{x x x x}^{(3)}\left(-\omega_{3} ; \omega_{1}, \omega_{1}, \omega_{1}\right) \quad\left(\omega_{1}=2 \pi c \tilde{v}_{1}, \tilde{v}_{1}=9480 \mathrm{~cm}^{-1}\right)
$$

of various solids, liquids and air have been measured. The results are summarized in Table 1.

The normalized signal $\bar{S}=\bar{\eta} / I_{10}^{2}\left(b_{+}\right)$averaged over a modulation period changes only slightly for the various substances. As an example at $5 \times 10^{9} \mathrm{~W} / \mathrm{cm}^{2}$ an energy conversion of $\bar{\eta} \simeq 5 \times 10^{-11}$ is obtained in water.

The $\left|\chi^{(3)}\right|$-values are presented in SI units. They are transformed to esu-units by multiplying the reported values with $9 \times 10^{8} /(4 \pi)[12]$. The relative error of the presented data is estimated to be $\Delta \chi^{(3)} / \chi^{(3)} \simeq \pm 0.2$. The $\left|\chi^{(3)}\right|$-value of air is small because of the reduced density of molecules in gaseous state. The nonlinear susceptibilities of the liquids and solids vary over three orders of magnitude. They are related to the electronic transition frequencies and transition strengths. An increase of $\chi^{(3)}$ is observed when $\omega_{3}$ approaches an absorption band (SF 10, SF 59, rutile, nitrobenzene, 2-nitrotoluene, carbon disulfide, allo-ocimene). Correspondingly, $\chi^{(3)}$ increases with growing refractive indices.

Instead of $\chi^{(3)}$ the third-order hyperpolarizability $\gamma^{(3)}$ may be used to characterize the media. It describes the nonlinearity per molecule and is given by [26]

$\gamma^{(3)}=\frac{24 \varepsilon_{0} \chi^{(3)}}{N L^{4}}$.

$N=N_{A} \varrho / M$ is the number density of molecules. $N_{A}$ $=6.022169 \times 10^{23} \mathrm{~mol}^{-1}$ is the Avogadro number, $\varrho$ the density and $M$ the molar mass. $L^{4}=\left(n_{1}^{2}+2\right)^{3}\left(n_{3}^{2}\right.$ $+2) / 81$ is the Lorentz local field correction factor. (Other definitions of $\gamma^{(3)}$ without factor 24 and $\varepsilon_{0}$ are sometimes used $[1,34,36]$.)

The hyperpolarizability values $\gamma^{(3)}$ are listed in Table 1 $\left(1 \mathrm{Cm}^{4} / \mathrm{V}^{3}=8.0888 \times 10^{24} \mathrm{esu}\right)$. They exhibit a similar dependence as $\chi^{(3)}$. In case of rutile $\gamma^{(3)}$ is reduced compared to $\chi^{(3)}$ due to the large local field correction term $L^{4}$. The hyperpolarizability of air has about the same value as the liquid water.

According to the anharmonic oscillator model $[25,26]$ the hyperpolarizability $\gamma^{(3)}$ is related to the linear polarizabilities $\gamma_{i}^{(1)}=\left(3 \varepsilon_{0} / N\right)\left(n_{i}^{2}-1\right) /\left(n_{i}^{2}+2\right)(i=1,3)$ by

$\gamma^{(3)}\left(-\omega_{3} ; \omega_{1}, \omega_{1}, \omega_{1}\right)=\xi \frac{6 m}{f^{2} e^{4}} \gamma_{1}^{(1) 3} \gamma_{3}^{(1)}$,

where $\xi$ is the anharmonic coupling constant, $m$ the electron mass, $e$ the electron charge and $f$ the oscillator strength. Equation (18) leads to $\chi^{(3)} \propto\left(n_{1}^{2}-1\right)^{3}\left(n_{3}^{2}-1\right)$ (Miller's rule [25]). The effective anharmonic coupling constant $\xi / f^{2}$ is listed in Table 1 . It is proportional to $\gamma^{(3)} /\left[\gamma_{1}^{(1) 3} \gamma_{3}^{(1)}\right]$. The data indicate strong anharmonic coupling constants for substance with small $\gamma^{(3)}$-values ( $\mathrm{LiF}$, water, air) while for substances with large nonlinearity $\gamma^{(3)}$ grows less rapidly 
Table 1. Third-order nonlinear susceptibilities and data relevant for their calculation (temperature $23^{\circ} \mathrm{C}$ )

\begin{tabular}{|c|c|c|c|c|c|c|c|c|}
\hline \multirow[t]{2}{*}{ Substances } & \multirow[t]{2}{*}{$n_{1}{ }^{a}$} & \multirow[t]{2}{*}{$n_{3}{ }^{\mathrm{a}}$} & $x_{1}$ & $x_{3}$ & \multirow{2}{*}{$\begin{array}{l}\bar{\eta} / I_{10}^{2}\left(b_{+}\right) \\
{\left[10^{-30} \mathrm{~cm}^{4} / \mathrm{W}^{2}\right]}\end{array}$} & \multirow{2}{*}{$\begin{array}{l}\left|\chi^{(3)}\right| \\
{\left[10^{-23} \mathrm{~m}^{2} / \mathrm{V}^{2}\right]}\end{array}$} & \multirow{2}{*}{$\begin{array}{l}\left|\gamma^{(3)}\right| \\
{\left[10^{-61} \mathrm{Cm}^{4} / \mathrm{V}^{3}\right]}\end{array}$} & \multirow{2}{*}{$\begin{array}{l}=/ f^{2} \\
{\left[10^{51} \mathrm{~m}^{-2} \mathrm{~s}^{-2}\right]}\end{array}$} \\
\hline & & & {$[\mathrm{cm}$} & & & & & \\
\hline
\end{tabular}

\section{Solids}

$\begin{array}{lll}\text { Fused silica } & 1.4501^{\mathrm{c}} & 1.4769^{\mathrm{c}} \\ \text { Glass Bk7 }^{\mathrm{b}} & 1.5070^{\mathrm{d}} & 1.5392^{\mathrm{d}} \\ \text { Glass SF10 }^{\mathrm{b}} & 1.7024^{\mathrm{d}} & 1.8144^{\mathrm{d}} \\ \text { Glass SF59 }^{\mathrm{b}} & 1.9085^{\mathrm{d}} & 2.1233^{\mathrm{d}} \\ \text { LiF } & 1.3870^{\mathrm{c}} & 1.4032^{\mathrm{c}} \\ \text { Calcite } \mathbf{E}_{1} \| c & 1.4800^{\mathrm{c}} & 1.5040^{\mathrm{c}} \\ \text { Calcite } \mathbf{E}_{1} \perp c, \mathbf{k}_{1} \perp c & 1.6429^{\mathrm{c}} & 1.6968^{\mathrm{c}} \\ \text { Rutile } \mathbf{E}_{1} \| c & 2.7447^{\mathrm{c}} & 4.25^{\mathrm{e}} \\ \text { Rutile } \mathbf{E}_{1} \perp c, \mathbf{k}_{1} \perp c & 2.4823^{\mathrm{c}} & 3.69^{\mathrm{e}}\end{array}$

$\begin{array}{lcc}0 & 0 & 3.2 \\ 0 & 0.053 & 3.2 \\ 0 & 22.6 & 4.5 \\ 0 & 45.6 & 6.2 \\ 0 & 0 & 1.0 \\ 0 & 0 & 3.7 \\ 0 & 0 & 1.1 \\ 0 & 2 \times 10^{4 \mathrm{e}} & 30 \\ 0 & 4 \times 10^{4 \mathrm{e}} & 34\end{array}$

3.6
4.7
32
87
1.2
3.6
5.2
2800
2000

\section{Liquids}

Water

Water $+6 \mathrm{~mol} / 1 \mathrm{KI}$

Methanol

Ethanol

Acetone

$\mathrm{CCl}_{4}$

Benzene

Benzonitrile

Nitrobenzene

Tuoluene

2-nitrotoluene

$\mathrm{CS}_{2}$

1,5-hexadiene

$c, t 2,4$-hexadiene

$t, t$ 2,4-hexadiene

Allo-ocimene

$\begin{array}{ll}1.3252^{\mathrm{f}} & 1.3487^{\mathrm{f}} \\ 1.4391^{\mathrm{g}} & 1.5034^{\mathrm{g}} \\ 1.3225^{\mathrm{h}} & 1.3416^{\mathrm{h}} \\ 1.3547^{\mathrm{i}} & 1.3778^{\mathrm{i}} \\ 1.3511^{\mathrm{i}} & 1.3771^{\mathrm{i}} \\ 1.4498^{\mathrm{f}} & 1.4848^{\mathrm{f}} \\ 1.4286^{\mathrm{h}} & 1.5518^{\mathrm{h}} \\ 1.5080^{\mathrm{h}} & 1.5861^{\mathrm{h}} \\ 1.5258^{\mathrm{h}} & 1.6371^{\mathrm{h}} \\ 1.4774^{\mathrm{h}} & 1.5402^{\mathrm{h}} \\ 1.5236^{\mathrm{i}} & 1.6195^{\mathrm{i}} \\ 1.5928^{\mathrm{f}} & 1.7395^{\mathrm{f}} \\ 1.3915^{\mathrm{h}} & 1.4294^{\mathrm{h}} \\ 1.4345^{\mathrm{j}} & 1.5120^{\mathrm{k}} \\ 1.4187^{\mathrm{l}} & 1.4896^{\mathrm{l}} \\ 1.4799^{\mathrm{j}} & 1.5494^{\mathrm{k}}\end{array}$

$\begin{array}{lcc}0.172 & 2.3 \times 10^{-3} & 1.9 \\ 0.144 & 0.2 & 4.8 \\ 0.112 & 0 & 1.6 \\ 0.031 & 0 & 2.7 \\ 0 & 0 & 3.5 \\ 0 & 0 & 5.4 \\ 0 & 0 & 3.3 \\ 0 & 2.48 & 1.3 \\ 0 & 2.25^{\mathrm{n}} & 2.2 \\ 0.01 & 0 & 2.0 \\ 0 & 5900^{\mathrm{o}} & 1.3 \\ 0 & 175^{\mathrm{p}} & 4.8 \\ 0.43 & 0.031 & 3.1 \\ 0.2 & 1.6 & 3.5 \\ 0 & 0.74 & 2.4 \\ 0 & 133 & 3.6\end{array}$

$1.0002490^{\mathrm{m}} \quad 1.0002598^{\mathrm{m}} \quad 0$

$0 \quad 1.5$

$\begin{array}{cc}0.97 & 1.01 \\ 1.1^{\mathrm{q}} & 0.70^{\mathrm{q}} \\ 5.6^{\mathrm{r}} & 0.34^{\mathrm{r}} \\ 5.9^{\mathrm{s}} & 0.56^{\mathrm{s}} \\ 0.14 & 14.8 \\ 1.2 & 0.32 \\ 1.1 & 0.11 \\ 8.8 & 0.82 \\ 12.9 & 1.6\end{array}$

Gases

Air ( 0.9 bar)

\author{
h Extrapolated from [17] using single \\ oscillator model [18] \\ i Extrapolated from [19] using single \\ oscillator model [18] \\ j Extrapolated from own measurements [20] \\ using single oscillator model [18] \\ k Own measurements [20] \\ 1 [21] \\ $\mathrm{m}$ [15] \\ n $[22]$
}

$\begin{array}{ccc}2.2 & 0.57 & 9.7 \\ 11.1 & 23.5^{\mathrm{t}} & 33.7^{\mathrm{u}} \\ 1.6 & 0.93 & 0.65 \\ 2.6 & 1.95 & 0.23 \\ 3.3 & 3.2 & 0.15 \\ 6.2 & 5.9 & 0.038 \\ 17.0 & 14.8 & 1.39 \\ 8.5 & 7.1 & 0.023 \\ 19 & 14.9 & 0.042 \\ 7.0 & 6.7 & 0.024 \\ 13.0 & 11.8 & 0.019 \\ 41.1 & 15.1 & 0.23 \\ 5.2 & 7.1 & 0.033 \\ 12.7 & 14.4 & 0.052 \\ 8.6 & 10.4 & 0.046 \\ 14.7 & 21.6 & 0.012\end{array}$

9.7

65

0.23

0.038

1.39

0.042

0.024

.23

0.033

0.046

012

4.0 c Linear interpolated from [15] a Absolute
b From
c Linear
d Schott
e [16]
f Linear
g [18]

a Absolu
b From
c Linear
d Schott
e $[16]$
f Linear
g $[18]$ ar interpolated from [17] than $\gamma_{1}^{(1) 3} \gamma_{3}^{(1)}\left(\xi / f^{2}\right.$ decreases $)$. A similar behaviour was reported in [28].

In Table 2 the measured $\chi_{x x x x}^{(3)}\left(-\omega_{3} ; \omega_{1}, \omega_{1}, \omega_{1}\right)$ values are compared with reported electronic thirdorder nonlinear susceptibility contributions $\chi_{x x x x \text {, el }}^{(3)}\left(-\omega_{4} ; \omega_{1}, \omega_{2}, \omega_{3}\right)$. The third-harmonic generation is caused by electronic nonlinearity. Our data are in reasonable agreement with most reported numbers (good agreement with [34]). In case of 6 molar KI dissolved in water $\chi_{x x x x}^{(3)}\left(-\omega_{3} ; \omega_{1}, \omega_{1}, \omega_{1}\right)$ is about a half of $\chi_{x x x x}^{(3)}\left(-\omega_{3} ; \omega_{2}, \omega_{2},-\omega_{1}\right)$ with $\omega_{2}=2 \omega_{1}$. The enlargement of $\chi^{(3)}\left(-\omega_{3} ; \omega_{2}, \omega_{2},-\omega_{1}\right)$ responsible for four wave mixing seems to be due to a two-photon resonance contribution $\left(2 \omega_{2}\right.$ near to electronic transition in KI solution). The nonlinear "electronic" susceptibilities obtained from optical Kerr effect measurements with picosecond lasers [37-39] are about an order of magnitude larger than the electronic nonlinear susceptibilities obtained from third harmonic and four-photon frequency mixing experiments. This fact indicates that the main contribution to the fast part of the Kerr constant is still due to molecular effects of short (subpicosecond) response time and not of pure electronic origin. Nonlinear susceptibility contributions with subpicosecond response times have been observed recently $[40,41]$. 
Table 2. Electronic third-order nonlinear susceptibilities $\chi_{x x x x \times, \text { el }}^{(3)}\left(-\omega_{4}: \omega_{1}, \omega_{2}, \omega_{3}\right)$

\begin{tabular}{|c|c|c|c|c|}
\hline \multirow[t]{3}{*}{ Substance } & \multicolumn{3}{|c|}{ Wavelength $\lambda_{i}=2 \pi c / \omega_{i}$} & \multirow{3}{*}{$\begin{array}{l}\chi_{\text {rxxxx. el }}^{(3)}\left(-\omega_{4} ; \omega_{1}, \omega_{2}, \omega_{3}\right) \\
{\left[10^{-15} \mathrm{esu}\right]}\end{array}$} \\
\hline & $i_{1}$ & $i_{2}$ & $i_{3}$ & \\
\hline & \multicolumn{3}{|l|}{$[\mathrm{nm}]$} & \\
\hline \multicolumn{5}{|l|}{ Solids } \\
\hline Fused silica & 1055 & 1055 & 1055 & $2.6^{\mathrm{a}}$ \\
\hline Fused silica & 694.3 & 694.3 & $-\quad 745.7$ & $10^{\mathrm{b}}$ \\
\hline Fused silica & 557 & 557 & -- 594 & $7^{\mathrm{c}} \cdot 3.8^{\mathrm{d}}$ \\
\hline Glass Bk7 & 1055 & 1055 & 1055 & $3.4^{\mathrm{a}}$ \\
\hline Glass $\left(n_{D}=1.516\right)$ & 1055 & 1055 & 0 & $3.8^{\mathrm{e}}$ \\
\hline Glass BSC & 1060 & 1060 & 1060 & $8^{\mathrm{f}}$ \\
\hline Glass BSC & 557 & 557 & -- 594 & $9.2^{\mathrm{c}}, 6.2^{\mathrm{d}}$ \\
\hline $\mathrm{LiF}$ & 1055 & 1055 & 1055 & $0.9^{\mathrm{a}}, 3^{\mathrm{f}}, 3.6^{\mathrm{g}}$ \\
\hline $\mathrm{LiF}$ & 694.3 & 694.3 & 694.3 & $2^{b}$ \\
\hline $\mathrm{LiF}$ & 1890 & 1890 & 1890 & $1.7^{\mathrm{h}}$ \\
\hline $\mathrm{LiF}$ & 557 & 557 & - 594 & $3.4^{\mathrm{c}}, 1.9^{\mathrm{d}}$ \\
\hline Calcite & 1055 & 1055 & 1055 & $2.6^{\mathrm{a}} \cdot 3.7^{\mathrm{a}}$ \\
\hline Calcite & - & - & - & $14^{\mathrm{c}}, 7^{\mathrm{d}} \cdot 4^{\mathrm{d}}$ \\
\hline \multicolumn{5}{|l|}{ Liquids } \\
\hline Water & 1055 & 1055 & 1055 & $1.6^{\mathrm{a}}$ \\
\hline Water & 527.5 & 527.5 & -1055 & $1.5^{\mathrm{i}}$ \\
\hline $6 \mathrm{~mol} \mathrm{KI}$ in water & 1055 & 1055 & 1055 & $8.0^{\mathrm{a}}$ \\
\hline $6 \mathrm{~mol} \mathrm{KI}$ in water & 527.5 & 527.5 & -1055 & $19^{i}$ \\
\hline $\mathrm{CCl}_{4}$ & 1055 & 1055 & 1055 & $4.5^{\mathrm{a}}$ \\
\hline $\mathrm{CCl}_{4}$ & 555 & 555 & -587 & $11^{\mathrm{j}}$ \\
\hline $\mathrm{CCl}_{4}$ & 1060 & 1060 & 0 & $8.7^{\mathrm{e}}$ \\
\hline Benzene & 1055 & 1055 & 1055 & $12.2^{\mathrm{a}}$ \\
\hline Benzene & 1890 & 1890 & 1890 & $15.8^{\mathrm{h}}$ \\
\hline Benzene & 570 & 532 & -532 & $20^{\mathrm{k}}$ \\
\hline Benzene & 1060 & 1060 & 0 & $10.6^{\mathrm{e}}$ \\
\hline Benzene & 555 & 555 & -587 & $17.5^{\mathrm{j}} \cdot 18.4^{1}$ \\
\hline Benzene & - & - & - & $14^{\mathrm{d}}$ \\
\hline Nitrobenzene & 1055 & 1055 & 1055 & $14^{\mathrm{a}}$ \\
\hline Nitrobenzene & 555 & 555 & -587 & $40^{\mathrm{j}}$ \\
\hline Nitrobenzene & 1060 & 1060 & 0 & $16.7^{\mathrm{e}}$ \\
\hline Nitrobenzene & 1060 & -1060 & 530 & $300^{p}$ \\
\hline 2-nitrotoluene & 1055 & 1055 & 1055 & $9.3^{\mathrm{a}}$ \\
\hline 2-nitrotoluene & 1060 & -1060 & 530 & $330^{p}$ \\
\hline $\mathrm{CS}_{2}$ & 1055 & 1055 & 1055 & $30^{\mathrm{a}}$ \\
\hline $\mathrm{CS}_{2}$ & 570 & 532 & -532 & $86.5^{\mathrm{k}}$ \\
\hline $\mathrm{CS}_{2}$ & 555 & 555 & -587 & $87^{j}$ \\
\hline $\mathrm{CS}_{2}$ & 1060 & 1060 & 0 & $30^{\mathrm{e}}$ \\
\hline $\mathrm{CS}_{2}$ & 1060 & -1060 & 530 & $120^{\mathrm{q}}$ \\
\hline Allo-ocimene & 1055 & 1055 & 1055 & $11^{\mathrm{a}}$ \\
\hline Allo-ocimene & 1890 & 1890 & 1890 & $35^{\mathrm{m}}$ \\
\hline \multicolumn{5}{|l|}{ Gases } \\
\hline $\begin{array}{l}\text { Air }\left(p_{0}=1 \mathrm{bar}\right. \\
\left.T_{0}=273 \mathrm{~K}\right)^{\mathrm{n}}\end{array}$ & 1055 & 1055 & 1055 & $4.9 \times 10^{-4 \mathrm{a}}, 4.4 \times 10^{-4 \mathrm{f}}$ \\
\hline $\begin{array}{l}\operatorname{Air}\left(p_{0}=1 \mathrm{bar}\right. \\
\left.\quad T_{0}=273 \mathrm{~K}\right)^{\mathrm{n}}\end{array}$ & 694.3 & 694.3 & 694.3 & $2 \times 10^{-3}$ or $7.9 \times 10^{-3 o}$ \\
\hline a This work & \multicolumn{4}{|l|}{ k [33] } \\
\hline${ }^{\mathrm{b}}[11]$ & \multicolumn{4}{|l|}{${ }^{1}[35]$} \\
\hline c [29] & \multicolumn{4}{|l|}{$m[36]$} \\
\hline d $[30]$ & \multirow{2}{*}{\multicolumn{4}{|c|}{${ }^{\mathrm{n}} \chi^{(3)}\left(\operatorname{air}, p_{0}, T_{0}\right)=\frac{p_{0}}{p} \frac{T}{T_{0}} \chi^{(3)}(\operatorname{air}, p, T)$}} \\
\hline e $[34]$ & & & & \\
\hline $\mathrm{f}[3]$ & \\
\hline g $[4]$ & \multirow{4}{*}{\multicolumn{4}{|c|}{$\begin{array}{l}\text { p From optical Kerr effect }\left(\chi_{x x x x, \text { el }}^{(3)}\left(-\omega_{2}\right.\right. \\
n, \text { refractive index at } \omega_{2} ; n_{2}^{e} \text { nonlinear elec } \\
\text { index [12] [37] (see text) } \\
\text { q From optical Kerr effect [39] (see text) }\end{array}$}} \\
\hline h [4] & & & & \\
\hline${ }^{i}[26]$ & & & & \\
\hline j $[32]$ & & & & \\
\hline
\end{tabular}




\section{Conclusions}

We described a technique for the accurate measurement of third-order nonlinear susceptibilities responsible for third-harmonic generation. The technique was applied to determine nonlinear susceptibility and hyperpolarizability values of some liquids, solids and air. The described method may be easily extended to the measurement of other third-order nonlinear susceptibilities $\chi_{i j k l}^{(3)}\left(-\omega_{4} ; \pm \omega_{1}, \pm \omega_{2}, \pm \omega_{3}\right)$ responsible for four-wave interaction processes.

Acknowledgements. The authors thank Prof. M. Maier for helpful discussions. They are indepted to Th. Ascherl for technical assistance, to W. Leupacher for assistance in the later part of the work, and to Dr. G. Meyer for help in the numerical analysis. They thank the "Deutsche Forschungsgemeinschaft" for financial support and the "Rechenzentrum" of the University for providing computer time.

\section{References}

1. J.F. Ward, G.H.C. New: Phys. Rev. 185, 57 (1969)

2. R. Fischer, L.W. Wieczorek: Ann Physik 7. Folge, 35, 389 (1978)

3. C.C. Wang, E.L. Baardsen: Phys. Rev. 185, 1079 (1969); Phys. Rev. B 1, 2827(E) (1970)

4. J.P. Hermann: Opt. Commun. 9, 74 (1973)

5. S.A. Akhmanov, L.B. Meisner, S.T. Parinov, S.M. Saltiel, V.G. Tunkin: Sov. Phys. JETP 46, 898 (1977)

6. P.P. Bey, J.F. Guiliani, H. Rabin: IEEE J. QE-4, 932 (1968); Phys. Lett. 26 A, 128 (1968)

7. R.K. Chang, L.K. Calbraith: Phys. Rev. 171, 993 (1968)

8. J.C. Diels, F.P. Schäfer: Appl. Phys. 5, 197 (1974)

9. H.P. Puell, C.R. Vidal: IEEE J. QE-14, 364 (1978)

10. S.R.J. Brueck, H. Kildal: Opt. Lett. 2, 33 (1978)

11. P.D. Maker, R.W. Terhune: Phys. Rev. 137, A 801 (1965)

12. R.W. Minck, R.W. Terhune, C.C. Wang: Appl. Opt. 5, 1595 (1966)

13. A. Penzkofer, D. von der Linde, A. Laubereau: Opt. Commun. 4, 377 (1972)

14. A. Penzkofer, W. Kaiser: Opt. Quant. Electron. 9, 315 (1977)
15. D.E. Gray (ed.): American Institute of Physics Handbook, 3rd ed. (McGraw-Hill, New York 1972)

16. M. Cardona, G. Harbeke: Phys. Rev. 137, A 1467 (1965)

17. K.H. Hellwege, A.M. Hellwege (eds.): Landolt-Börnstein, 6th edn., Vol. 2, Part 8 (Springer, Berlin, Heidelberg, New York 1962)

18. A. Penzkofer, H. Glas, J. Schmailzl: Chem. Phys. 70, 47 (1982)

19. International Critical Tables of Numerical Data, Physics, Chemistry and Technology, Vol. VII, ed. by E.W. Washburn (McGraw-Hill, New York 1930)

20. K. Schmid, A. Penzkofer: Appl. Opt. 22, 1824 (1983)

21. Beilsteins Handbuch der Organischen Chemie, 4. edn., 3. Ergänzungswerk, Erster Band, 1. Teil, ed. by F. Richter (Springer, Berlin, Heidelberg, New York 1958) p. 985

22. DMS UV Atlas of Organic Compounds, Vol. I, eds. by H.H. Perkampus, I. Sandeman, C.J. Timmons (Verlag Chemie, Weinheim; Butterworth, London 1971) p. D8/5

23. L. Dede, A. Rosenberg: Ber. Dtsch. Chem. Ges. 67, 147 (1934)

24. E. Pietsch (ed.): Gmelins Handbuch der Anorganischen Chemie, 8. edn. (Verlag Chemie, Weinheim 1970)

25. F. Zernike, J.E. Mitwinter: Applied Nonlinear Optics (Wiley, New York 1973)

26. A. Penzkofer, J. Schmailzl, H. Glas: Appl. Phys. B 29, 37 (1982)

27. R.C. Miller: Appl. Phys. Lett. 5, 17 (1964)

28. K.C. Rustagi, J. Ducuing: Opt. Commun. 10, 258 (1974)

29. M.D. Levenson: IEEE J. QE-10, 110 (1974)

30. R.W. Hellwarth: Prog. Quant. Electron. 5, 1 (1977)

31. C.C. Wang: Phys. Rev. B 2, 2045 (1970)

32. M.D. Levenson, N. Bloembergen: J. Chem. Phys. 60, 1323 (1974)

33. A. Owyoung: Opt. Commun. 16, 266 (1976)

34. B.F. Levine, C.G. Bethea: J. Chem. Phys. 63, 2666 (1975)

35. M.D. Levenson, N. Bloembergen: Phys. Rev. B 10, 4447 (1974)

36. J.P. Hermann, J. Ducuing: J. Appl. Phys. 45, 5100 (1974)

37. J. Etchepare, G. Grillon, R. Muller, A. Orszag: Opt. Commun. 34, 269 (1980)

38. J. Etchepare, G. Grillon, R. Astier, J.L. Martin, C. Bruneau, A. Antonetti: In Picosecond Phenomena III, ed. by K.B. Eisenthal, R.M. Hochstrasser, W. Kaiser, A. Laubereau, Springer Series Chem. Phys. 23 (Springer, Berlin, Heidelberg, New York 1982) p. 217

39. P.P. Ho, R.R. Alfano: Phys. Rev. A 20, 2170 (1979)

40. J.M. Halbout, C.L. Tang: Appl. Phys. Lett. 40, 765 (1982)

41. B.I. Greene, R.C. Farrow: Chem. Phys. Lett. 98, 273 (1983) 